\title{
Breves considerações filosóficas acerca da relação arte-educação ambiental
}

\author{
Marcos Antônio Pimentel Pequeno \\ Universidade Federal da Paraíba
}

\section{Resumo}

Este artigo resulta de uma investigação acerca da relação arte-educação ambiental. O nosso objetivo consiste em contribuir com a referida relação, evidenciando que a mesma necessita ser fundamentada por uma concepção de sensibilização associada a uma visão ampliada de educação e ecologia. Nesse sentido, apresentaremos um quadro sucinto das principais correntes do debate ambiental e uma reflexão acerca da dimensão educacional do problema ecológico.

Palavras-chave: arte-educação, sensibilização, ecologia.

\section{Abstract}

This article arises from a research about the relationship between the environmental matter and the art-education issue. Our goal is to contribute to this relationship, by showing that it needs to be sustained by a concept of sensitization associated with a broader view of education and ecology. In this sense, we present a brief picture of the mainstream of the environmental debate and a reflection on the educational extent of the ecological problem.

Keywords: art-education issue, sensitization, ecology.

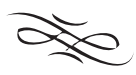

A relação arte-educação é, antes de tudo, um desafio epistemológico que pode ser nutrido por investigações filosóficas. A reflexão de Ana Mae Barbosa acerca da referida relação, efetuada no final dos anos 80 (que permanece atual em sua essência), transcende o seu âmbito imediato, uma vez que a sua exaltação da importância do conhecimento como norteador da arte-educação é algo que pode ser estendido a todos os setores da atividade humana. Ela revela que nos 16 anos (de 1973 a 1989) de ensino obrigatório das artes no Brasil não foi desenvolvida a qualidade da estética da arte-educação nas escolas. Este quadro estaria associado à baixa qualidade escolar que atinge todas as outras áreas 
de ensino. Assim, diz ela: “a atual situação da educação geral no Brasil é dramática. (...) Como resultado, nós chegamos a 1989 tendo arte-educadores com uma atuação bastante ativa e consciente, mas com uma formação fraca e superficial no que diz respeito ao conhecimento de arte-educação e arte" (BARBOSA, 2015, p. 173-174). Nessa perspectiva, o exercício da atividade artística nos processos de educação ambiental precisa ser fundamentado pelo conhecimento da complexidade e abrangência que envolve a questão ambiental, remetendo, pois, aos vários níveis das relações dos homens entre si e com a natureza, o que nos convida a considerar e refletir acerca das inúmeras dimensões do problema ecológico ${ }^{1}$.

A tese central que iremos desenvolver neste artigo é que a eficácia da relação arte-educação ambiental necessita de uma concepção ampliada de sensibilização embasada em uma epistemologia que reflita acerca dos fundamentos, alcances e limites da arte, educação e ecologia, reportando a um questionamento crítico das relações dos homens consigo mesmos e com a natureza.

Um dos grandes desafios pedagógicos de nossa época é reaproximar a arte da educação (KRAEMER/SASSE, 2015), convidando o educador a romper com o reducionismo tecnicista que atribui aos processos pedagógicos o objetivo de priorizar a formação de mão-de-obra qualificada ${ }^{2}$, acarretando, assim, um prejuízo para a formação integral do educando, uma vez que a dimensão estética e moral é desvalorizada. Visando a correção de tal distorção, pensamos que a sensibilização poderia vir a ser utilizada pela arte-educação ambiental como instrumento auxiliar na formação integral do educando.

Consideramos que os sentimentos e emoções podem desempenhar um papel relevante na construção de uma consciência ambiental. As vivências afetivas (enquanto primeiro momento do processo de aprendizagem) tendem a dar aos educandos as ferramentas emocionais primárias para iniciar um processo educativo cujo objetivo maior é a compreensão de que o problema ecológico atinge a humanidade e todos os outros seres. Nesse sentido, por exemplo, por meio de processos pedagógicos (teóricos e/ou práticos) que despertem sentimentos e emoções (medo, raiva, tristeza, compaixão etc.) quanto ao futuro da humanidade, o indivíduo tenderá a situar-se emocionalmente como parte do problema e, com isso, poderá construir elementos cognitivos para o enfrentamento teórico e prático das questões ambientais, assumindo, assim, uma efetiva postura de preservação ecológica. O reconhecimento da sensibilização como primeiro momento da formação da consciência ecológica evidencia que os sentimentos e as emoções são a base primária do ser humano, a partir da qual nos tornamos seres de liberdade, razão,

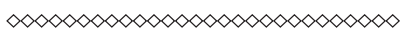

1 Neste artigo, enfatizaremos a dimensão educacional do problema ecológico. Faremos breve indicação das demais dimensões e citaremos nas referências bibliográficas algumas obras pertinentes e norteadoras do debate ambiental.

2 É sabido que na Grécia antiga a atividade artística era um instrumento indissociável da formação educacional do indivíduo, revelando, assim, além do estético, a sua contribuição para o desenvolvimento da dimensão epistemológica, ética e política do educando. 
linguagem etc. Nessa perspectiva pedagógica, a arte-educação assumiria a função de carro-chefe, uma vez que a manifestação artística está intima e essencialmente ligada à sensibilidade, dela brotando, de modo interligado, a própria sensibilização e os múltiplos processos cognitivos que acarretam vivências capazes de levar à conscientização, criação etc. Tal constatação permite-nos fazer a seguinte indagação: como a sensibilização pode ser utilizada na arte-educação com vistas ao enfrentamento da questão ambiental? Pensamos que a busca por respostas nos remete, de imediato, ao cerne do próprio debate ecológico atual.

A questão ambiental ${ }^{3}$ é um dos mais desafiadores e inquietantes problemas enfrentados pelo homem contemporâneo. A nossa reflexão filosófica acerca da referida questão (termo que designa o conjunto de problemas e temas referentes ao meio ambiente) constata que esse tema assume a dimensão de problema ecológico em duplo sentido. No primeiro nível, a questão ambiental é física e diz respeito ao próprio significado etimológico da palavra ecologia (oikos mais logos, que significa um estudo ou reflexão sobre nossa morada maior), pois a totalidade de nosso planeta, o seu equilíbrio sistêmico está ameaçado pelo efeito agressivo e devastador de algumas práticas humanas, gerando tensão, conflito, incertezas, dúvidas, controvérsias no próprio seio daquele que refletem sobre o meio ambiente. Num segundo momento, a questão ambiental envolve a complexa totalidade de nosso modelo de civilização, gerando também as mesmas supracitadas características de crise que nos remetem à palavra ecologia e que abarca, hoje, significados múltiplos no campo do conhecimento, da militância ecológica, das políticas de preservação ambiental, da crítica ao mundo contemporâneo etc. A referida complexidade revela sérios conflitos cuja dimensão política de amplitude global nos convida a refletir acerca da possibilidade de defesa da ideia de que uma ecologia democrática seria, politicamente, o caminho mais bem indicado para criar as condições de superação do problema ecológico.

Dos temas passíveis de reflexão filosófica, o ecológico tem se constituído como um dos mais complexos, pois nele se entrelaçam, simultaneamente, questões de natureza onto-antropológica, ética, estética, política, econômica, cultural, jurídica, educacional, social, técnico-científica, histórica etc., ou seja, ele traduz, em seu conjunto, a complexidade do homem, do mundo e da relação entre ambos.

As reflexões filosóficas que movimentaram o debate ecológico do século XX aos nossos dias podem ser sintetizadas em duas posturas básicas que essencialmente põem em discussão a relação antropocentrismo/ biocentrismo.

O biocentrismo ecológico é uma postura ambiental fundamentada, majoritariamente, por uma crítica ao modelo de civilização ocidental considerado antropocêntrico. Os principais alvos de crítica são as democracias liberais do ocidente, a economia capi-

$\infty<\infty<\infty<\infty<\infty<\infty<\infty<\infty<\infty<\infty<\infty$

3 A constatação de que a questão ambiental nos remete a complexos conflitos (de ordem material e subjetiva) que envolvem a relação homem-natureza, repercutindo na totalidade da Terra, nos convida a utilizar o referido termo, neste trabalho, com o significado amplo de questão ou problema ecológico. 
talista e a tecnociência. São várias as fontes do biocentrismo. O seu arcabouço teórico aglutina propostas ou teorias diferentes e até opostas, transitando entre a extrema-direita e a extrema-esquerda. Destacamos os seguintes expoentes.

O primeiro, Aldo Leopold (1887-1948), é considerado por muitos como um dos precursores da ecologia profunda e um dos mais influentes expoentes do ambientalismo norte-americano, ao lado de Rachel Carson (1907-1964). Ele defendeu a preservação da natureza selvagem por meio de uma ética da terra que propõe uma revisão da relação homem-natureza e que se baseia nas críticas ao progresso oriundo do desenvolvimento tecnológico e econômico. A sua obra A sandy county almanac (traduzida em português como Pensar como uma montanha), publicada em 1949, que reúne uma coletânea de ensaios ecológicos, constitui uma tentativa de inversão da postura antropocêntrica em defesa do biocentrismo ou ecocentrismo.

O segundo expoente é a Ecologia profunda, um termo criado por Arne Naess (1912-2009), no início da década de 70, cujo significado original designa, em termos gerais, as diretrizes teóricas e uma postura de enfrentamento das questões ambientais guiadas por um holismo biocêntrico. A ecologia profunda apresenta, apesar de suas diferenças de cunho conceitual (que envolvem aspectos políticos, ideológicos, éticos, metafísicos, culturais etc.), uma uniformidade que é explicitada em sua defesa do biocentrismo.

O livro Ecologia profunda (1985), de Bill Devall e George Sessions, representa uma síntese dos princípios básicos e das práticas ambientais que caracterizam o movimento ecológico cuja denominação é a mesma do título do referido texto, por isso (o livro) pode ser visto como o manifesto do supracitado movimento. O livro Ecologia profunda é composto por uma coletânea, na qual inúmeros autores expõem os seus pensamentos e propõem ações ambientais favoráveis ao biocentrismo ${ }^{4}$ em oposição ao antropocentrismo que é entendido, aqui, como o alicerce básico da visão dominante da sociedade Ocidental. Nesse sentido, a ecologia profunda reivindica mais do que simples reformas em nosso modelo de civilização; ela exige algo mais radical. Dentre os seus representantes destacamos Michel Serres e Hans Jonas

Michel Serres (1930-), crítico severo dos fundamentos humanistas e antropocêntricos que dão sustentação teórica ao nosso modelo de civilização, é um dos expoentes do biocentrismo ao propor a celebração de um contrato natural que seria um meio de regular as relações econômicas que, através da concorrência, intensificam a violência objetiva global, bem como a dominação sobre os homens. A viabilidade do referido contrato natural dependeria essencialmente de um processo educativo que instruiria a pessoa numa dimensão global, integrando ciência, sociedade e natureza por intermédio daquele que Serres chama de o terceiro instruído.

Publicado em 1979, O princípio responsabilidade, de Hans Jonas (1903-1993), con-

$\infty<\infty<\infty<\infty<\infty<\infty \times \infty \times \infty \times \infty \times \infty<\infty<\infty<$

4 Além dos textos de Bill Devall e de George Sessions, a referida obra apresenta as ideias biocêntricas de inúmeros autores, inclusive as de Arne Naess, o principal mentor da ecologia profunda. 
cebe o conceito de responsabilidade (Verantwortung) como categoria ética central, como guia fundamental de decisões que almejem garantir um futuro ecologicamente digno às gerações vindouras. Nesse sentido, ele critica todas as éticas tradicionais, consideradas antropocêntricas por não terem vinculado a natureza à responsabilidade humana, pois estiveram ocupadas com questões referentes ao aqui e agora.

O terceiro expoente do biocentrismo é o ecofeminismo (termo que surgiu no final dos anos 70 e foi utilizado pela primeira vez por Françoise D’Eaubonne), que é um movimento ambiental preocupado em detectar e denunciar as causas do problema ecológico e apontar soluções numa perspectiva que inclua a mulher como principal protagonista da defesa do meio ambiente e de um novo modelo de civilização. Tal proposta é estimulada pela ideia de que, até o presente momento, o Ocidente teria sido governado por uma lógica patriarcal de caráter dicotômico e dualista, baseada na exploração da natureza, da mulher e dos países pobres, o que teria desencadeado, assim, o próprio problema ecológico. Nesse sentido, denunciando aquilo que é denominado de sistema capitalista patriarcal mundial como a principal causa objetiva do referido problema, o ecofeminismo rejeita tal sistema por ele conceber "a diferença como hierárquica e a uniformidade como a pré-condição para a igualdade" (MIES/SHIVA, 1997, p.10).

O biocentrismo também encontra respaldo na proposta de libertação animal ${ }^{5}$, sugerida por Peter Singer, que tem como alvo principal a eliminação do que ele denomina especismo, ou seja, "o preconceito ou a atitude tendenciosa de alguém a favor dos interesses de membros da própria espécie, contra os de outras" (SINGER, 2010, p.11). A referida eliminação geraria, entre outras coisas, uma menor agressão ambiental na produção de alimentos. Partindo do pressuposto de que a igualdade é uma ideia moral, Singer assevera que os interesses de um ser afetado por uma ação devem ser levados em conta e receber o mesmo peso que os interesses semelhantes de qualquer outro ser. Singer considera a capacidade de sofrer e sentir dor o pré-requisito essencial para um ser ter algum interesse. Nesse sentido, não haveria justificativa moral para desconsiderar o sofrimento de um ser senciente.

Em sentido contrário ao biocentrismo, defendendo um antropocentrismo moderado que vise o equilíbrio da relação homem-natureza, estão aqueles que propõem reformulações e mudanças em nosso modo de ser, mantendo, porém, intacto o substrato antropocêntrico de algumas categorias fundamentais que nutriram a modernidade, como razão, liberdade, democracia, igualdade, direito etc. Nessa perspectiva, destacamos o filósofo francês Luc Ferry e os ambientalistas Michael Shellenberger e Ted Nordhaus.

Luc Ferry, um dos maiores expoentes contemporâneo da defesa de uma ecologia democrática, apresentada em sua obra A nova ordem ecológica (1994), possui o mérito de, com rigor metodológico e conceitual, tentar passar em revista crítica as teses centrais

$\infty<\infty<\infty<\infty<\infty<\infty<\infty<\infty<\infty<\infty<\infty<\infty$

5 Tal proposta convida-nos a não comer, inicialmente (numa progressão gradativa rumo ao vegetarianismo), alimentos oriundos da indústria de produção de alimentos que infligem sofrimentos aos animais não humanos. 
das principais correntes e posturas ambientais que refletem sobre o problema ecológico atual. Nesse sentido, Ferry põe em discussão um tema que foi alvo de ataques de pensadores avessos à modernidade, qual seja: o humanismo.

A proposta de Luc Ferry concernente a uma ecologia democrática exige, para o seu fortalecimento, uma crítica interna da própria democracia, bem como justificar a sua face reformista, uma vez que ela pretende manter intacto aquilo que ele considera $o$ melhor da herança iluminista, ou seja, a autonomia do indivíduo, a laicidade, o humanismo jurídico, a democracia etc. Nessa perspectiva, ele defende um humanismo crítico e não-metafísico que venha a assumir deveres para com os outros seres. Ferry afirma que a ampliação de direitos aos outros seres da natureza (que é uma das reivindicações do biocentrismo) exige uma ecologia global com repercussões políticas e econômicas que, em casos extremos, tende a negar a totalidade do mundo moderno, atingindo, pois, toda a sua herança humanista.

Decorridos pouco mais de vinte anos da publicação de A nova ordem ecológica, de Luc Ferry, foi publicada, nos textos de Michael Shellenberger e Ted Nordhaus, uma recente proposta de ecologia democrática pautada na exaltação do avanço tecnológico como meio mais eficaz para promover, numa perspectiva liberal-consensual-global, o desenvolvimento econômico e a preservação ambiental.

Shellenberger e Nordhaus publicaram, em 2004, o ensaio The death of environmentalism (A morte do ambientalismo) cujo objetivo maior é, ao mesmo tempo, denunciar a visão estreita dos ambientalistas para o enfrentamento do problema ecológico e mostrar que uma alternativa progressista de amplitude mundial é o melhor caminho para tentar solucionar as questões ambientais.

Um texto recente dos dois autores, intitulado Mais civilização, publicado em 2012, esclarece e amplia os conteúdos defendidos no ensaio ( $A$ morte do ambientalismo), escrito em 2004. O texto Mais civilização exalta a necessidade de se manter e acelerar os avanços tecnológicos como o meio mais eficaz para escaparmos do impasse ecológico que nós mesmos criamos, ou seja, o desenvolvimento tecnológico deve ser incentivado e associado ao avanço de um conjunto de elementos que eles sintetizam na expressão "mais civilização".

O desenvolvimento tecnológico sempre foi o meio que possibilitou a sobrevivência humana em seu relacionamento com a natureza. Ele ajudou a humanidade a perseguir os objetivos de emancipação da natureza, do tribalismo, da escravidão, da pobreza. Ademais, a nossa crescente dependência tecnológica associada ao interesse majoritário de crescimento econômico (que a maioria dos países reivindica), leva-nos a considerar, seriamente, a alternativa tecnológica como o meio mais bem indicado para atender às demandas humanas e enfrentar o problema ecológico.

A proposta de Michael Shellenberger e Ted Nordhaus é o ponto culminante do debate ecológico contemporâneo, uma vez que ela entrecruza as polêmicas entre antropocentrismo e biocentrismo, liberalismo e ambientalismo, sugerindo o diálogo e o consenso (na forma de alianças que aglutinem valores e interesses) como instrumentos 
de construção de alternativas tecnológicas que viabilizem o desenvolvimento material da civilização e a preservação ambiental.

Uma proposta de ecologia democrática para o enfrentamento da questão ambiental necessita ser, a nosso ver, complementada por alguns elementos que não foram acentuados pelos referidos autores, quais sejam: o papel da educação, da sensibilização e do Estado enquanto gestor ambiental. Esses elementos, consideramos essenciais, numa perspectiva democrática, para o enfrentamento da questão ambiental.

$\mathrm{O}$ embate entre biocentrismo e antropocentrismo revela a complexidade da questão ambiental. A defesa de uma ecologia democrática convida-nos a considerar, de maneira crítica e integrada, as várias dimensões do problema ecológico ${ }^{6}$. Nessa perspectiva, a dimensão educacional necessita ser analisada no contexto sociocultural em que está inserida.

A dimensão sociocultural do problema ecológico nos convida a considerar a inseparabilidade entre a referida dimensão e o ambiente, uma vez que as formas de organização social orientadas por valores, crenças, ideias, posturas, exercem influência sobre a natureza e o modo como a vemos.

A sociedade global é moldada pelo uso de elementos produzidos pela herança econômica e tecnológica engendrada pela modernidade. As indústrias da moda e cultural, os meios de comunicação de massa (que filtram a informação e se sustentam por meio de propagandas que incentivam o consumo), o self-service, o celular, o asfalto e os automóveis, a Internet, o agronegócio, a indústria farmacêutica, a UTI, os fechados condomínios e as câmeras de segurança, a produção industrial de alimentos de origem animal (da carne ao leite), os produtos de consumo e os alimentos industrializados, os preservativos, a pílula anticoncepcional, dentre outros itens, são conquistas da humanidade. Nesse sentido, a emergência do enfrentamento teórico e democrático do problema ecológico deve encarar a complexidade de uma sociedade global que a cada dia se torna mais dependente do desenvolvimento econômico e do uso crescente de tecnologias, pois o não reconhecimento desse fato, movido por ideologias ou interpretações diversas, pode acentuar o referido problema, o qual nos impõe a reflexão acerca de diretrizes que norteiem a adoção de medidas realizáveis de curto e médio prazos, desafiando-nos a pensar acerca de um elemento que está diretamente vinculado à dimensão sociocultural do problema ecológico: a educação, o que nos impõe o desafio de refletir acerca do referido elemento numa perspectiva ampliada que permita situar a arte como essencial instrumento de educação geral e ambiental.

Apesar de o fenômeno da globalização influenciar uma uniformização de políticas educacionais que visam, majoritariamente, à formação de mão-de-obra qualificada para o mercado, ele põe, ao mesmo tempo, a universalização de problemas decorrentes

$\infty<\infty<\infty<\infty<\infty<\infty<\infty<\infty<\infty<\infty<\infty<\infty$

6 Destacamos as seguintes dimensões do problema ecológico: ontometafísica, eticopolítica, juridicolegislativa, tecno-econômica, sociocultural e educacional, as quais, com exceção da última, não serão expostas devido às limitações de páginas exigidas por um artigo. 
de sua própria influência mundial, entre os quais, a questão ambiental e dos direitos humanos, ou seja, a globalização nos desafia a pensar o humano e a natureza (e a relação entre ambos) numa perspectiva universal. E aí reside a novidade: os países que levam a sério a educação devem priorizar conteúdos que possibilitem o aprendizado eficaz e concreto da língua materna (saber ler, interpretar, escrever e falar), da matemática e das demais ciências (saber calcular, desenvolver o raciocínio lógico, conhecer os fenômenos da natureza etc.), das artes e de seus processos de desenvolvimento de sensibilização, cognição e criação, associados e direcionados à educação ambiental e aos direitos humanos como um portal para as questões globais, ou seja, a educação necessita ser básica (ensino efetivo da língua materna, da matemática, das diversas ciências e das artes) e filosófica (a partir da aprendizagem do básico, pensar de modo universal) relacionando o indivíduo com o todo, ou com as totalidades que o envolvem (família, escola, sociedade, cultura, economia, política, ambiente etc.).

A educação ambiental deve estar associada a um processo de transmissão de conhecimentos básicos que permitam ao estudante construir um firme alicerce para a sua formação profissional e intelectual. Nesse sentido, pensamos que o educando necessita ser motivado (e aqui reside o aspecto fundamental) por processos de sensibilização que o levem a se situar, de modo emocional, como parte integrante dos problemas ambientais $^{7}$. Tudo isso associado ao objetivo de criar condições materiais e intelectuais que permitam ao educando construir e atingir um patamar crítico-reflexivo que o capacite a assumir uma postura de preocupação ambiental, pois, em caso diverso, há o perigo de a educação ambiental tornar-se mais uma disciplina a saturar de modo ineficaz a grade curricular escolar.

Apesar das controvérsias científicas que atingem, por exemplo, a questão do aquecimento global, o educador necessita revelar aos estudantes o teor de tal polêmica com informações precisas, alertando para o fato de que, mesmo que tal aquecimento seja ocasionado por ciclos naturais e não por consequência direta da atividade humana, é sensato, ante tal dúvida, que cada indivíduo dê a sua contribuição em favor do meio-ambiente. Nesse sentido, o educando deve ser informado, entre outras coisas, que o consumo doméstico de água e energia corresponde a menos de dez por cento, sendo a indústria e o agronegócio os setores que consomem a quase totalidade do percentual restante. Essa informação poderá fortalecer a compreensão de que, além da contribuição individual que cada um é convidado a assumir, existe um contexto maior que transcende o âmbito individual e remete para estruturas (políticas, sociais, econômicas etc.) que regem de modo marcante o funcionamento da sociedade. Nesse sentido, a educação deve

$\infty<\infty<\infty<\infty<\infty<\infty<\infty<\infty<\infty<\infty<\infty<\infty$

7 Se é verdade que o ser humano é movido, majoritariamente, pelos seus desejos, o que inclui a influência das emoções, então a sensibilização quando corretamente estimulada é um poderoso instrumento para a ação. Nesse sentido, a sensibilização pode ser eficaz independente da faixa etária e do nível escolar do indivíduo, uma vez que existem pessoas pobres e analfabetas com mais sensibilidade ambiental que outras de nível sócio econômico e educacional privilegiados. 
ser entendida como um amplo processo de ensino e aprendizagem que simultaneamente incorpora e transcende o âmbito escolar, atingindo, pois, todo o corpo sócio-político-cultural.

Defendemos que o regime democrático ainda é o melhor caminho para o estabelecimento do equilíbrio ambiental, haja vista que este é uma das condições básicas para a continuidade daquele, uma vez que a democracia se afigura como o melhor meio para equilibrar a relação economia-ecologia e tal equilíbrio é uma condição para o seu desenvolvimento. Nesse sentido, uma opção não democrática talvez pudesse vir, por outros meios, a equilibrar a referida relação, mas há o temor de tal alternativa suprimir, em nome da preservação incondicional do meio ambiente, aquilo que é essencial ao humano, a sua liberdade. Eis, pois, que se impõe à educação o desafio de ser um instrumento de fortalecimento da democracia e de uma postura de enfrentamento das questões ambientais.

Não adianta defender o lema "educação é fundamental" sem a criação de uma política pública de educação que esteja assentada numa adequada infraestrutura escolar e em diretrizes pedagógicas bem fundamentadas. Convém ainda apostar em uma educação que, além de oferecer conteúdos tecnicistas, forneça saberes teóricos e práticos capazes de contribuir para o desenvolvimento cultural, ético e intelectual do indivíduo e, consequentemente, do corpo social.

A necessidade de fundamentar as pedagogias de ensino escolar numa rica concepção de educação é um desafio de amplitude mundial que encontra obstáculos em peculiaridades locais, regionais e nacionais, mas que revela também uma tendência global comum: a priorização do ensino tecnicista como alicerce do desenvolvimento econômico. Enquanto nos países ricos tal prioridade tem o objetivo de garantir e, se possível, ampliar a opulência material já obtida, nos países pobres e emergentes a meta é superar a miséria e atingir o progresso econômico. Porém, nesse caso, trata-se de um desafio ainda maior por causa da carência de professores qualificados e de fatores estruturais de ordem social, econômica e cultural, que dificultam o próprio desenvolvimento do ensino tecnicista. Nesse contexto, falar de educação de qualidade pode soar, à primeira vista, como devaneio. De qualquer forma, aliada a essa a formação de tendência tecnicista, não se pode negar que há também um despertar para a necessidade de que a educação ambiental faça parte também dos conteúdos curriculares do sistema formal de ensino e que tal disciplina, a nosso ver, esteja associada a um processo de sensibilização ecológica.

Além de informações precisas, a educação ambiental deve priorizar conteúdos que expressem verdades. Assim, é aconselhável que qualquer sugestão de amor à natureza, respeito pelos outros seres, seja acompanhada pela revelação de que vivemos em um complexo modelo de civilização que é movido por uma postura antropocêntrica que está entranhada nas várias dimensões que caracterizam o ser humano, sendo, pois, de difícil possibilidade a superação radical do referido antropocentrismo, restando-nos, assim, tentar moderá-lo, redimensioná-lo para a preservação ambiental. Desse modo, é conveniente ressaltar que a preocupação ambiental é essencialmente uma preocupação 
antropocêntrica, uma vez que o problema ecológico foi ocasionado pelo próprio homem que necessita, agora, encontrar soluções para o enfrentamento do referido problema. Essa evidência permite colocar a seguinte indagação: que concepção de homem é mais adequada e necessária à educação ambiental? A filosofia, nos últimos duzentos anos, revelou-nos que o ideal kantiano, de uma conduta ética guiada por uma razão prática, autônoma e legisladora capaz de estabelecer princípios universais, encontra vários obstáculos que impedem a sua eficácia devido às influências oriundas da história (em sua dimensão social, política, econômica, cultural etc.), da linguagem, do inconsciente e das emoções.

É óbvio que o ser humano não é 100\% razão ou emoção, mas um ente complexo em que a história, a linguagem, o inconsciente exercem influência sobre o pensamento e os nossos referenciais teóricos. Nesse sentido, é sábio utilizar as emoções como um instrumento que ajude na construção de uma postura ecológica, o que põe em discussão um dos elementos essenciais do processo de educação ambiental. Embora não utilize o termo sensibilização, Hans Jonas exalta o medo como um veículo auxiliar de construção de uma ética da responsabilidade preocupada com o futuro da humanidade. Nessa perspectiva, as políticas de educação ambiental poderiam traçar diretrizes que possibilitassem às escolas a utilização de vídeos que revelam a degradação ambiental, convidar pessoas que são suas vítimas diretas (ou que estão envolvidas em suas atividades profissionais) para darem seus depoimentos e, principalmente, levar os estudantes a lixões, abatedouros industriais, fazendas de criação intensiva, espaços urbanos residenciais destituídos de saneamento básico etc. Nesse caso, vale reinventar a máxima: sinto, logo existo como sujeito crítico e transformador.

A sensibilização ${ }^{8}$, associada a informações precisas e a conteúdos verdadeiros, é um instrumento que necessita ser incorporado (tanto pela educação como pelos meios de comunicação de massa) ao objetivo de despertar nos indivíduos aquelas emoções básicas (medo, raiva, tristeza, afeto, alegria) que poderão gerar sentimentos de solidariedade, compaixão, respeito etc. capazes de auxiliar o indivíduo no enfrentamento das questões ambientais, possibilitando-lhe efetuar indagações do tipo: se eu e os outros não fizermos algo, talvez falte água, eletricidade, alimentos etc. para mim e para os outros? Que me cabe fazer? Que devo esperar que os outros façam?

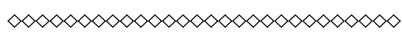

8 Convém salientar que estamos nos referindo a um tipo de sensibilização de caráter espontâneo que a educação ambiental poderia utilizar visando à construção individual de uma postura ecológica numa perspectiva democrática de ensino. Nesse sentido, a educação ambiental apresenta-se como uma das alternativas plausíveis que necessita ser associada aos múltiplos caminhos que devem ser direcionados para o complexo enfrentamento democrático do problema ecológico. Por outro lado, tememos que o agravamento futuro do problema ecológico e uma consequente escassez de alimentos, água, energia etc. (que encareceria o consumo atingindo os mais carentes e necessitados e, inclusive, a própria abundância dos países ricos) nos exija uma sensibilização forçada, o que reforçaria o dito popular de que o sapato só incomoda quando o calo aperta e dói. Nesse caso, seriamos forçados, de modo vital, a questionar de maneira radical os nossos hábitos de consumo, estilo de vida etc. e por em xeque toda a herança da modernidade, cujas consequências seriam temerárias e imprevisíveis, colocando-nos dilemas que, penso, transitariam entre a democracia e a barbárie. 
A reflexão acerca da educação envolve uma expressão-chave que é utilizada pelo ambientalismo mundial: a necessidade de desenvolvimento de uma consciência ambiental. Tal expressão convida os educadores a assumirem o objetivo de "conscientizar" ambientalmente os seus estudantes. Mas, é possível conscientizar alguém e fazer com que tal conscientização resulte efetivamente em práticas de enfrentamento das questões ambientais? Alguém é capaz de, real e efetivamente, conscientizar outrem? Afinal, quem conscientiza o conscientizador? Não seria mais prudente que o objetivo de "conscientizar" alguém fosse precedido e norteado pelo oferecimento de infraestruturas socioeducacionais (às quais já nos referimos) que possibilitassem ao educando construir a sua própria consciência crítico-reflexiva, contribuindo, assim, para o próprio fortalecimento da conduta preservacionista? O objetivo educacional de conscientizar não seria equivocado, uma vez que existem indivíduos com baixa estatura intelectual que possuem mais consciência ambiental que indivíduos com alta escolaridade?

Em todo caso, se o educador insiste com o objetivo de "conscientizar", então a sensibilização poderia ser incluída e utilizada, uma vez que ela permite atingir as emoções básicas necessárias para motivar o indivíduo a abraçar ações de preservação ambiental. Nesse sentido, a sensibilização também possui o mérito de envolver ambientalmente os indivíduos independentemente de seu nível social e escolar, do pobre ao rico, do analfabeto ao doutor. E aí reside a sua fundamental relevância como motivadora do processo de educação ambiental, pois ela é, ao mesmo tempo, incisiva e imediata, bem como abrangente, uma vez que as emoções influenciam diretamente o pensamento e a conduta dos seres humanos. Nesse sentido, a sensibilização, concebida como um instrumento que pode auxiliar processos educacionais que visem a oferecer aos educandos meios concretos para a construção de sua qualificação profissional, bem como de sua postura crítico-reflexiva, poderia vir a contribuir como força motivadora essencial da constituição de uma razão ecológica aglutinadora de pensamentos, emoções e sentimentos que orientem escolhas e decisões capazes de assumir a responsabilidade ambiental.

A sensibilização é um processo inerente ao mundo psíquico que remete à palavra sensibilidade que significa a capacidade de sentir emoções e sentimentos, atingindo de modo positivo ou não a nossa afetividade que pode ser definida como um receptáculo físico e mental a partir do qual se manifestam as próprias emoções e sentimentos. De modo mais amplo, como assevera Ballone, a afetividade envolve as representações, as vivências e os sentimentos (BALLONE, 2013, p.01).

As vivências são o somatório das nossas experiências pessoais, as quais envolvem representações (lembranças, significados, compreensões etc.), afecções e atitudes. As vivências são acompanhadas por sentimentos (medo, ansiedade, alegria, raiva, angústia, apreensão etc.) que são as nossas respostas às referidas vivências. Daí a importância de vivências que produzam sentimentos e representações favoráveis à preservação do meio ambiente, afinal, se é verdade que as vivências causam sentimentos, então por que não propiciar ou priorizar aquelas que possibilitem uma postura favorável à causa ecológica? Nesse sentido, bastaria apenas estimular vivências direcionadas para o referido objetivo, 
ou seja, por meio de um pedagógico processo de sensibilização seria possível atingir a afetividade dos indivíduos estimulando, assim, os seus sentimentos e representações. Desse modo, por intermédio da afetividade, as nossas vivências são transformadas em sentimentos e representações. Ela é a fonte de valor subjetivo e objetivo, que nos ajuda a apreender o mundo. Por isso, ela necessita ser estimulada, de modo saudável, para contribuir com o desenvolvimento ético, cultural, intelectual e emocional do indivíduo.

A importância da afetividade no processo educacional (que, como vimos, abrange toda a vida do indivíduo) é um tema da psicologia genética que encontra em Vygotsky um de seus maiores expoentes. A sua relevância reside na defesa da ideia de que pensamento e afetividade são instâncias inseparáveis que interagem reciprocamente.

Nessa perspectiva, pensamento e afetividade mantêm um relacionamento que alicerça e desenvolve essencialmente a própria constituição da consciência que, segundo Oliveira, "seria a própria essência da psiquê humana, constituída por uma inter-relação dinâmica, e em transformação ao longo do desenvolvimento, entre intelecto e afeto, atividade no mundo e representação simbólica, controle dos próprios processos psicológicos, subjetividade e interação social” (OLIVEIRA in: LA TAILLE, 1992, p.79).

Os atuais estudos psicogenéticos acerca da importância da afetividade na constituição do ser humano são a continuidade de uma tradição filosófica empirista que remonta a David Hume (1711-1776) que defendeu, em sua obra Tratado da natureza humana, a tese de que as emoções são a fonte da conduta moral.

\section{Considerações finais}

Concluímos a presente reflexão reafirmando a ideia de que a sensibilização (considerando-se, também, a sua influência no agir moral), além de sua possível contribuição ao processo geral de educação da sociedade, é um estratégico instrumento de mobilização que poderá ser útil ao fortalecimento de uma ecologia democrática. Nesse sentido, as artes são convidadas, democraticamente, a assumirem o papel de protagonistas da sensibilização ambiental na educação que está entranhada na dimensão sociocultural do ser humano.

Destacamos, também, que a motivação e o uso da afetividade por intermédio de processos pedagógicos de sensibilização, além de contribuir com o desenvolvimento das potencialidades dos indivíduos, pode ser utilizada para estimular a atuação do Estado como gestor ambiental, bastando, para isso, que os governos democráticos sejam sensibilizados para executar tal objetivo, o que motivaria tais governos (considerando a sua estrutura administrativa e de comando) a exercer a função de intermediários entre Estado e sociedade, visando encontrar meios para suscitar o diálogo, a compreensão e o consenso necessários para o enfrentamento do problema ecológico. 


\section{Referências bibliográficas}

BALLONE, G.J. Afetividade. Texto disponível em http:/www.psiqweb.med.br/ site $/$ ?area $=\mathrm{NO} /$ LerNotícia\&idNotícia $=62$

BARBOSA, Ana Mae. Arte-educação no Brasil: realidade hoje e expectativas futuras. Artigo disponível em: www.scielo.br/pdf/ea/v3n7/v3n7a10

BOBBIO, Norberto. Sociedade e estado na filosofia política moderna. $2^{\text {a }}$ ed. São Paulo: Brasiliense, 1987. Janeiro: Paz e Terra, 1986.

O futuro da democracia: uma defesa das regras do jogo. Rio de Liberalismo e democracia. São Paulo: Brasiliense, 2000. Igualdade e liberdade. A era dos direitos.

BOFF, Leonardo. Ecologia: grito da Terra, grito dos pobres. Rio de Janeiro: Sextante, 2004 .

DALAI LAMA. Uma ética para o novo milênio. $4^{\mathrm{a}}$ Ed. Rio de Janeiro: Sextante, 2000 .

DEVALL, Bill / SESSIONS, George. Ecologia Profunda. Águas Santas - Portugal: Edições Sempre-em-Pé, 2004.

FERRY, Luc. A nova ordem ecológica: a árvore, o animal e o homem. São Paulo: Ensaio, 1994.

HABERMAS, Jürgen. Sobre a Constituição da Europa. São Paulo: Martins Fontes, 2012.

HUME, David. Tratado da natureza humana. São Paulo: Editora UNESP, 2009.

JONAS, Hans. O princípio Responsabilidade. Rio de Janeiro: Contraponto, Ed. PUC-RIO, 2006.

KANT, Immanuel. Ideia de uma história universal de um ponto de vista cosmopolita. São Paulo: Martins Fontes, 2011.

KRAEMER, Celso / SASSE, Fernanda. O conceito de arte e sua importância para a educação. Artigo disponível em: <proxy.furb.br/ojs/index.php/atosdepesquisa/article/ view/2271/1492>

LARRÈRE, Catherine / LARRÈRE, Raphael. Do bom uso da natureza. Lisboa: Piaget, 2000.

LA TAILLE, Yves de. Piaget, Vygotsky, Wallon: teorias psicogenéticas em discussão. 
São Paulo: Summus, 1992.

LEOPOLD, Aldo. Pensar como uma montanha. Águas Santas/Portugal: Edições Sempre-em-Pé, 2008.

MIES, Maria / SHIVA, Vandana. Ecofeminismo. Lisboa: Instituto Piaget, 1997.

NAESS, Arne. Ecology, community and lifestyle. New York: Cambridge University Press, 1989.

PELIZZOLI, M.L. Correntes da ética ambiental. 2a ed. Petrópolis: Vozes, 2002. A emergência do paradigma ecológico. Petrópolis: Vozes, 1999. Ética e meio ambiente para uma sociedade sustentável. Petrópolis: Vozes, 2013.

PEQUENO, Marcos Antônio Pimentel. Artigo: Liberdade, igualdade e ecologia. Revista Mosaicum, Ano 9, n. 16. Teixeira de Freitas, BA: Faculdade do Sul da Bahia, 2012.

PEQUENO, Marconi José Pimentel. 10 lições sobre Hume. Petrópolis: Vozes, 2012 a.

SERRES, Michel. Le Contrat Naturel. Paris: Éditions François Bourin, 1990. . O Contrato Natural. Lisboa: Instituto Piaget, 1991.

SHELLENBERGER, Michael / NORDAUS, Ted. The death of environmentalism (A morte do ambientalismo). Ensaio publicado em 2004.

. Mais civilização. Texto publicado em 13 de junho de 2012 pela Revista Veja, edição 2273 - ano 45 - n.24.

SINGER, Peter. Libertação animal. São Paulo: Martins Fontes, 2010.

TOSI, Giuseppe. Direitos Humanos: história, teoria e prática. João Pessoa: Editora Universitária/UFPB, 2005.

VERNANT, Jean-Pierre. As origens do pensamento grego. $4^{\text {a }}$ ed. São Paulo: Difel, 1984.

VYGOTSKY, Lev S. Pensamento e linguagem. 3.ed. São Paulo: Martins Fontes, 1991.

ZANOTELLI, Luiz Cláudio. Artigo: o ecologismo e a peste emocional. Sobral: Revista da Casa de Geografia de Sobral, ano 1. N.1 (1999). Texto disponível em: www. uvanet.br/rcgs/index.php/RCGS/article/viewFile/43/101 